\title{
Soil Liquefaction and Paste Tailings
}

\author{
K. Been Golder Associates Inc., United States of America
}

A.L. Li Golder Associates Ltd, Canada

\begin{abstract}
Liquefaction of soils is a well documented phenomenon, frequently resulting in catastrophic failures, environmental damage, financial loss and deaths. What seems to be less well appreciated is that liquefaction is simply another constitutive behaviour of soils that can be understood in terms of accepted physics and mechanics. Critical state theory is probably the most widely used mathematical model for the mechanics of soil behaviour since it captures the effect of density (or volume change) on soil behaviour. This paper presents an overview of how the behaviour of tailings (drained, undrained or cyclic resistance) can be quantified within the framework of critical state soil mechanics. It is postulated that paste at the time of deposition is slightly wetter than the critical state, and it is then possible to trace the change of state with the additional of more tailings and consolidation or desiccation. Knowledge of the in situ state allows the material behaviour to be described, and therefore engineering analyses can be carried out.
\end{abstract}

\section{Introduction}

Liquefaction is a phenomenon in which a soil loses much of its strength or stiffness for a relatively short time, but nevertheless long enough for slope or bearing capacity failures to occur. Liquefaction has historically been viewed as a very difficult problem because it was unpredicted and occurred under various conditions. It has been observed as coastal flow slides triggered by wave action, under railway embankments as trains pass, as failure of embankment dams during construction, as sand boils during earthquakes, as dam and slope failures after earthquakes and in offshore structures subject to cyclic ice loading.

There are many recorded cases of liquefaction failure of mine waste, and quite likely many more unrecorded cases and their triggers are diverse. A liquefaction induced flowslide of coal waste into the village of Aberfan in Wales (Bishop, 1973) was likely caused by the hydrogeological conditions at the site; artesian pressure in the underlying sandstone caused failure in the overlying less permeable materials. The Merriespruit failure in 1994 was a catastrophic flow slide failure of gold tailings (Fourie et al., 2001) triggered by overtopping and erosion of the impoundment. Mittal and Hardy (1977) describe failure of an oil sands tailings dyke in Canada, in which the rate of construction of the dyke was too rapid for pore pressure dissipation in the sand foundation, leading to liquefaction and lateral spreading of the loose beach sand. The Stava Mine tailings dam failure in 1985 was triggered by a rising phreatic surface in the upper dam and the initial failure caused the sand shell to liquefy and flow in a very rapid and dramatic manner (Morgenstern, 2001). One of the engineered earth fill retaining dykes of the Sullivan Mine in British Columbia failed suddenly in 1991 during routine dyke raising at a height of $21 \mathrm{~m}$ that was attributed to static liquefaction (Davies et al., 1998). In these cases, liquefaction failures occurred under static loading. Ishihara et al. (1990) describe seismically induced failures of the Hokkaido tailings dam (in 1968) and two dams at the Mochikoshi facility (in 1978).

The current trend towards paste and thickened tailings disposal means that liquefaction is becoming more rather than less important even though the slope of paste and thickened stacks is much flatter than typical downstream slope of a convention tailings dam. For conventional disposal of wet tailings within a retention dyke, it is only necessary to show that the retention structure (e.g. tailings dam) is stable under all conditions. However, if thickened or paste tailings are stacked without a retention structure, or only a small starter dyke at the toe of a slope, then stability of the tailings mass is important. There are current projects where the proposed top of the tailings stack is at least $100 \mathrm{~m}$ above the crest of a starter dyke ( $\mathrm{Li}$ et al., 2009).

Liquefaction of soils is a well documented phenomenon, but what seems to be less well appreciated is that liquefaction is simply another constitutive behaviour of soils that can be understood in terms of accepted 
physics and mechanics. In the early days empirical methods were almost exclusively used to study liquefaction, and unfortunately this approach has been vigorously propagated, partly because few credible alternatives have been put forward. A 1998 workshop titled the Physics and Mechanics of Liquefaction (Lade and Yamamuro, 1998) and the VELACS project (Arulanandan and Scott, 1993) documented more rigorous approaches based on centrifuge testing and numerical modeling but failed to bring these into mainstream engineering practice. However, in the approximately 40 years history of liquefaction study there have been significant advances in constitutive modeling of soil behaviour and even greater increases in numerical modeling power. It is no longer justified to ignore theoretical models and this paper provides a consistent, critical state soil mechanics framework to consider liquefaction of tailings materials.

\section{Mechanics of liquefaction}

Critical state theory is probably the most widely used mathematical model for the mechanics of behaviour for both cohesive and cohesionless soils since it captures the effect of density (or volume change) on soil behaviour. This propensity for soils to change volume during shearing is a key feature that distinguishes soils from many other materials. Liquefaction is a manifestation of contractive behaviour of soils during shearing, where the resultant pore water pressures further reduce the effective stress and the shear resistance resulting in a brittle, strain softening response.

The starting point for critical state theory is the critical state line (CSL). The CSL is simply the void ratio at which shearing takes place continuously without volume change. This is to all intents and purposes the critical void ratio first described by Casagrande (1936) and the steady state line measured by Castro (1969) in the laboratory. The key point is that when a soil is taken to large shear strains, the end point will be the critical state. Figure 1 illustrates the basic concepts. A void ratio - effective stress plot such as Figure 1 is called a state diagram as it describes the 'state' of a soil (just like pressure, volume and temperature describe the state of a gas). Soils above the CSL are 'looser' than critical, while those below are 'denser' than critical. Soils looser than critical will contract (or show positive pore pressure) and follow stress paths that take them to the critical state line. Dense soils will dilate (or show negative pore pressures) and also follow stress paths to the critical state line. Illustrative stress paths are shown in Figure 1.

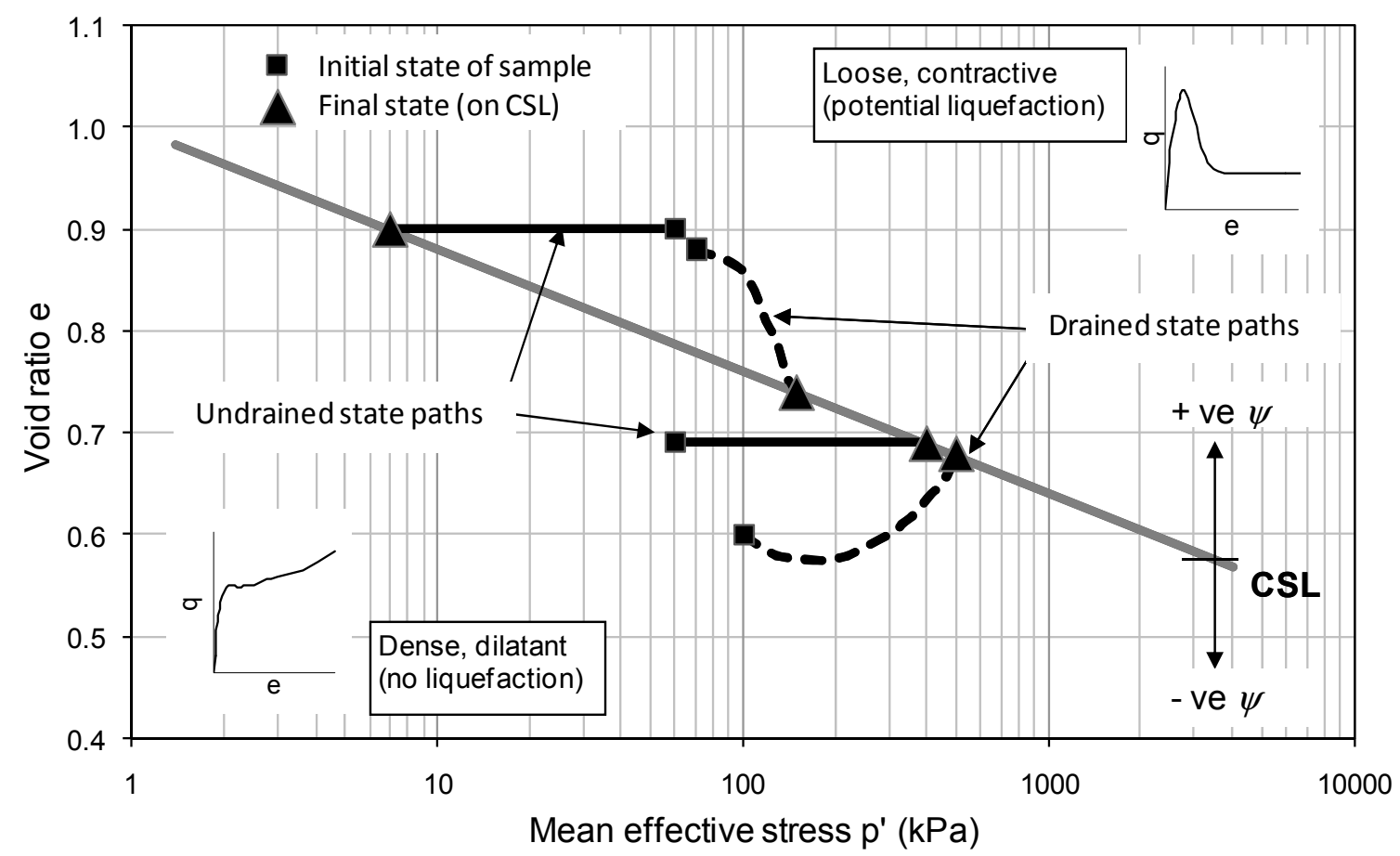

Figure 1 State diagram for cohesionless soils, showing typical triaxial test stress paths for loose and dense samples in drained (dashed lines) and undrained (solid lines) shear 
The vertical axis of Figure 1 could be defined as any of several variables: density, porosity, solids concentration, water content, specific volume or void ratio. For saturated tailings, there are one-to-one relationships between these variables, but one that excludes the effect of the specific gravity of the solid particles and the density of water is preferred. Void ratio, $e$, fits that requirement and is shown on Figure 1.

Figure 1 shows only monotonic (static loading) behaviour but liquefaction is more likely to occur under dynamic earthquake loading. Cyclic loading can lead to positive pore pressures even in dense soils, as illustrated in Figure 2. Liquefaction is considered to occur in this sample when the cyclic strains suddenly increase and the sample is no longer able to sustain the loading. At this time the pore water pressure is close to the confining stress and the sample stiffness is very low. This has led people to describe the soil as being in a fluid state (i.e. liquefaction), but this is an incorrect and misleading description. There is still grain to grain contact and effective stress between the soil particles, although the effective stresses are small. If the load is purely cyclic, the shear strains will cease once the loading stops, but if there is an unbalanced shear stress (or static bias on the cyclic stress) then strains may accumulate during the cyclic loading. Strains may continue after cyclic loading ceases until the pore pressures dissipate to the condition where the driving shear stresses are less than the shearing resistance of the soil.
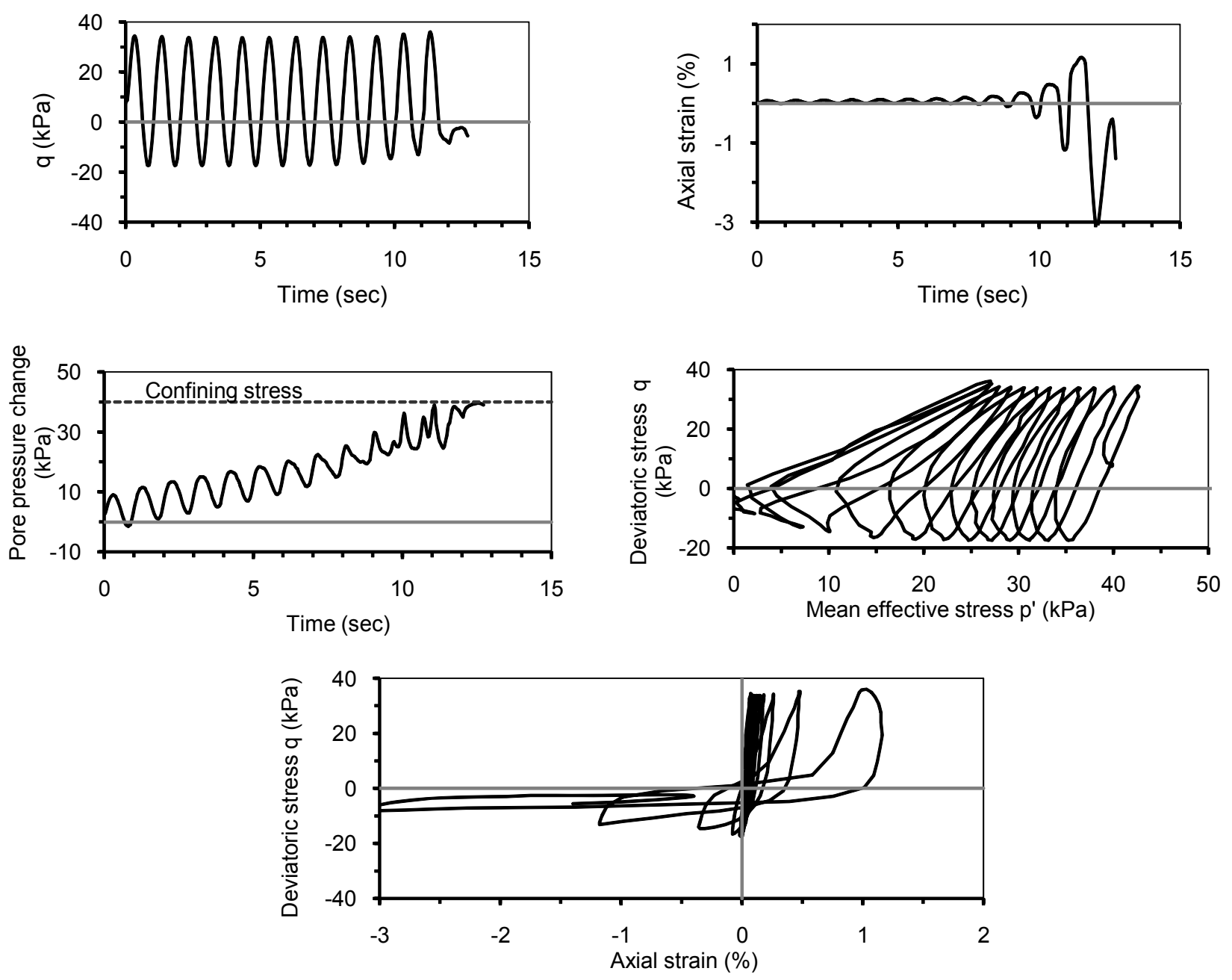

Figure 2 Cyclic triaxial test on dilatant Nevada sand. Note loss of stiffness when pore pressure approaches confining stress, and that mean effective stress is in general non-zero 


\section{Liquefaction failures in tailings facilities}

It is instructive to consider how the above discussion applies to a paste tailings stack. There are essentially three modes of liquefaction behaviour to consider based on the physical mechanisms:

1. As the tailings are deposited, the stress conditions on the underlying tailings or soils are changed and generally the shear stresses are increased. If the shear stress and associated shear strain also increase the pore pressure in the soils, then a condition may be reached where the shear strength of the soil is insufficient to resist the driving shear stress. The stack fails, but since the soil is loose and brittle the rate of failure is generally high. This is often called 'static liquefaction failure'.

2. During an earthquake, pore pressures are generated by the cyclic loading. In addition, there are increased dynamic stresses in the slope due to the ground motions. This combination of reduced strength (due to increased pore pressure) and increased loading can lead to dynamic slope instability. A good analogy would be a block on an inclined plane that is moving back and forth. As the plane moves in the down slope direction there is an increased normal force between the slope and the block, which is therefore stationary since the friction is increased by the increased normal force. When the direction reverses, however, the normal force is reduced and the block will slide down the slope until the movement is arrested by the next reversal in direction. Newmark (1965) suggested this block sliding analogy for analysis of slope displacements during earthquakes. Whether liquefaction occurs or not in this mechanism is immaterial. It only matters that the yield strength in the slope is exceeded during the cyclic loading, with the recognition that the yield strength does depend on the generated pore water pressures and could be very low as a result of liquefaction. This is called 'cyclic mobility failure' and may be followed by the third failure mode.

3. The third mode of liquefaction failure is where the high pore pressures generated during an earthquake cannot dissipate directly to a nearby free draining surface. This may occur because there are lower permeability clay or silt layers that impede drainage. What happens is that the pore water pressures are spread within the soil mass, potentially to zones of critical stress (e.g. near the base of a slope), which then leads to slope instability. If there is loose or brittle material in the slope, failure can be rapid in the form of a liquefaction flow slide, or it may less severe in what is called lateral spreading. This form of brittle post earthquake failure is common both in tailings dams (e.g. Ishihara et al., 1990) and water retention dams (De Alba, 1986; Seed et al., 1988), and is called a 'post liquefaction flow slide'.

While much research and focus has been placed on the cyclic behaviour of soils during earthquakes, i.e. failure mode two above, from an engineering and risk point of view it is the first and third failure modes that are more critical. As soon as the earthquake stops, it is the monotonic or static conditions that determine whether a catastrophic or runaway flow slide develops. The displacements that occurred during the earthquake itself are insignificant in the context of such large displacements. In addition, unless tailings are deliberately densified or improved after deposition, a large earthquake will almost inevitably result in high pore pressures in the tailings. So even if the slope is stable during the earthquake, stability after shaking under redistributed pore pressure conditions must be considered. This is fortunate for engineering, as monotonic behaviour of soils is much easier to model than cyclic response.

\section{Critical state framework for liquefaction}

It is not the intention to provide the mathematics of critical state soil mechanics in this paper, but it is important to appreciate that there are constitutive models for soil behaviour based on plasticity theory that incorporate the state of the soil as described below (e.g. Schofield and Wroth, 1968; Jefferies, 1993; Manzari and Dafalias, 1997; Li and Dafalias, 2000).

Consider the tailings states depicted on Figure 1. A simple quantification of the initial state is the distance from the critical state line. Void ratio on the critical state line is given by $e_{c}$, and distance from the CSL is then quantified by the parameter $\psi$ where $\psi=\mathrm{e}-\mathrm{e}_{\mathrm{c}}$ and is simply called the state parameter (Been and Jefferies, 1985). State parameter is positive for loose states above the CSL and negative for dense states below the CSL. 
The behaviour of cohesionless soils, i.e. sands and tailings, is dominated by dilatancy (which is the tendency to change volume when sheared). Since $\psi$ is a measure of the potential for volume change from the initial to the ultimate state, it turns out that many aspects of the behaviour of sands and tailings can be captured by simply considering the value of $\psi$. It is superior to using void ratio or relative density alone, because dilatancy can be suppressed by pressure. This effect of pressure is included in the value of $\psi$ through the slope of the critical state line.

The design challenge for paste tailings can therefore be simply stated:

1. Determine the in situ state $\psi$ of the tailings deposit.

2. Measure engineering behaviour of tailings as a function of $\psi$.

3. Carry out analyses using the appropriate engineering parameters.

The first two items are discussed in the rest of this paper.

\section{$5 \quad$ Engineering behaviour as a function of state}

Figure 3 shows the result of triaxial tests to determine the effective friction angle of several tailings materials, where the friction angle is plotted against $\psi$. The data all fall within a usefully narrow range, so that from an engineering perspective we can confidently state that if we know the state of the tailings we know the friction angle.

Next consider the undrained behaviour of loose tailings, which is of primary interest for liquefaction. Figure 4 shows the peak undrained shear strength, normalized to the initial confining stress, as a function of $\psi$ which in this case is positive. Here it is apparent that the peak undrained strength is less for looser tailings (higher positive values of $\psi$ ).

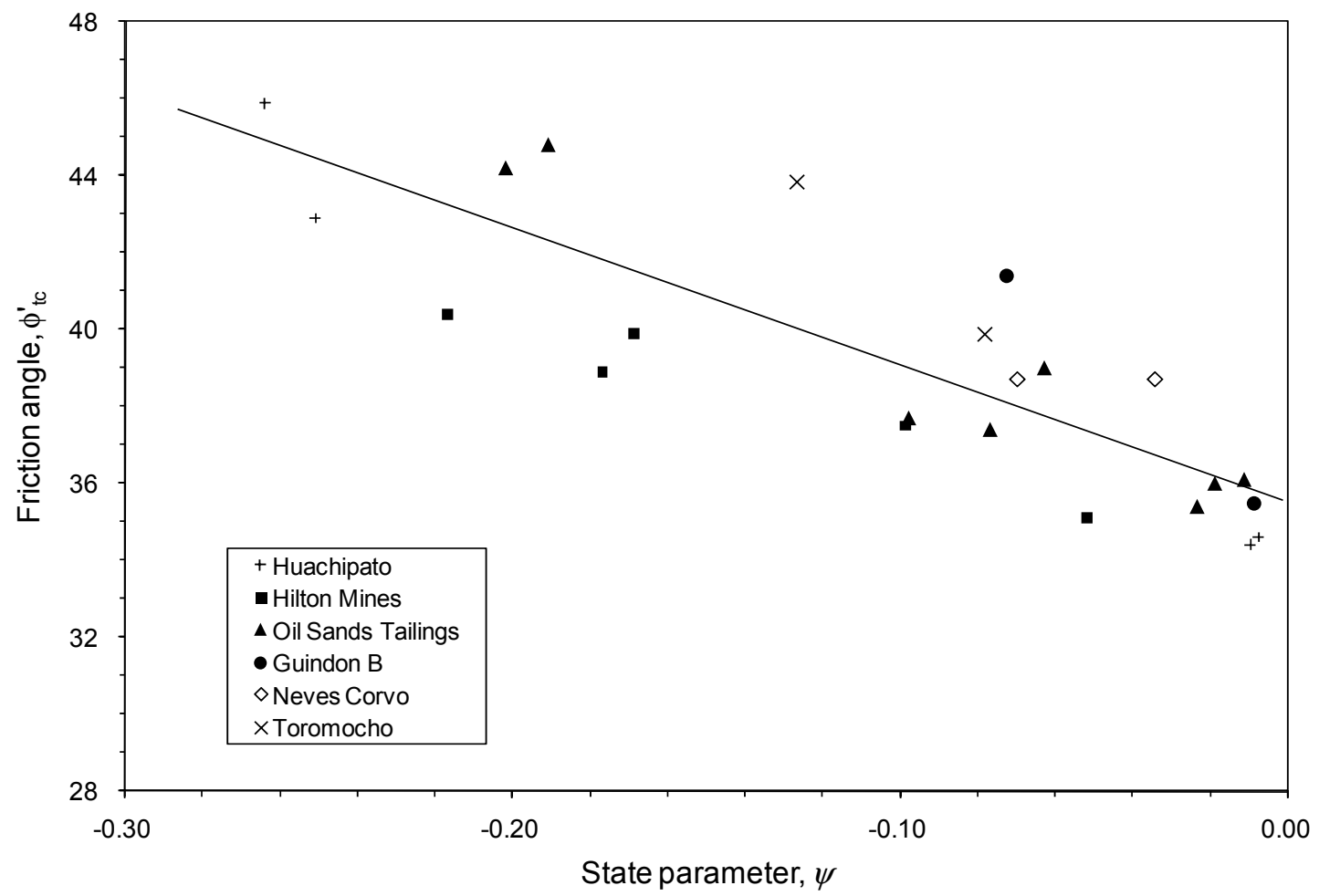

Figure 3 Drained friction angle as a function of state parameter for tailings materials 


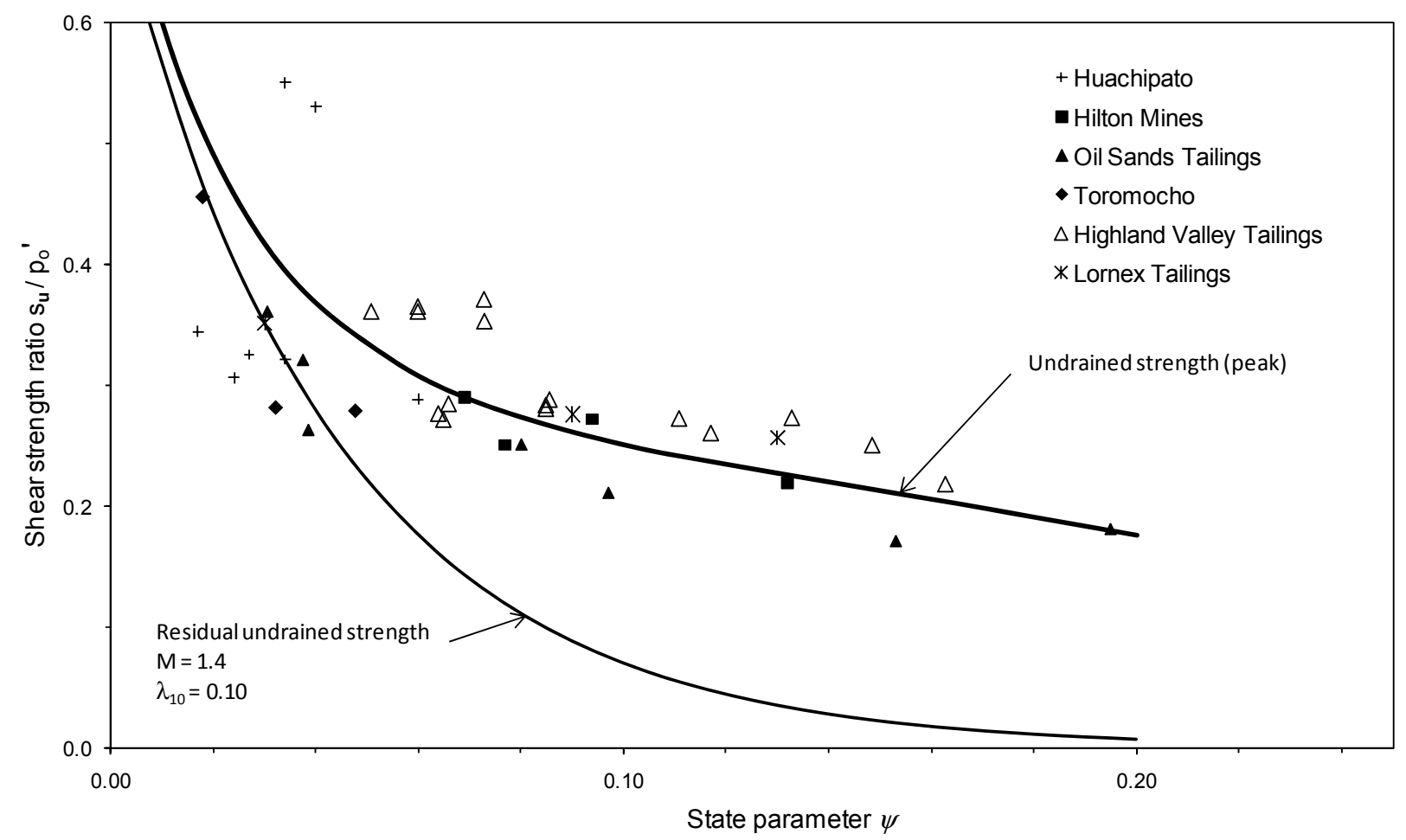

Figure 4 Peak undrained shear strength measured on tailings samples, and computed residual (critical state) strength

We can also use a little bit of mathematics to show the residual, large strain, strength of the tailings on Figure 4. Firstly, the critical state line is given by two equations:

$$
\begin{gathered}
e_{c}=\Gamma-\lambda_{10} \log \left(p^{\prime}\right) \\
q=M p^{\prime}
\end{gathered}
$$

Where $e_{c}$ is the void ratio on the critical state line, $\Gamma$ is the void ratio at the reference pressure $(1 \mathrm{kPa}$ in this case), $\lambda_{10}$ is the slope of the CSL on a semi-log plot (with the subscript 10 or $e$ to indicated if $\log$ to the base 10 or natural logarithms are being used), $p^{\prime}$ is the mean effective stress, $q$ is the deviatoric stress and $M$ is the stress ratio $\left(q / p^{\prime}\right)$ at the critical state. Then, since we are considering undrained or constant volume behaviour, the stress path must be horizontal on Figure 1, so that the initial void ratio of the tailings is the void ratio when it reaches the critical state. Using the definition of $\psi$ and Equations 1 and 2 one can derive the relationship between the critical state undrained shear strength and the initial state parameter:

$$
\frac{s_{r}}{p_{0}^{\prime}}=\frac{M}{2} \exp \left(-\frac{\psi}{\lambda_{e}}\right)
$$

Where $2.303 \lambda_{e}=\lambda_{10}$. Under the same theoretical frame work, Mayne (1980) derived correlations between undrained shear strength of clays and Cam Clay model parameters and demonstrated that the critical state theory gave rational and reasonable predictions of undrained shear strength of soils. The solid line on Figure 4 shows the computed critical state strength for an average value of $\lambda_{10}=0.105$ and $M=1.43$ for the tailings materials shown. Comparing the two lines, what is now also apparent is that the peak and critical state undrained shear strengths are approximately the same for values of $\psi$ close to zero, but the drop in shear strength from the peak to the critical state increases as the tailings becomes looser, i.e. $\psi$ increases. It is this brittleness or drop in shear strength from peak to residual that causes catastrophic flow failures. Equation 3 is important because it gives a value of residual (post liquefaction) shear strength when the in situ state of the material and its critical state line are known. 
A note of caution is warranted about the applicability of the residual shear strength relationship in Equation 3. There are two key assumptions: the first is that the value of $\psi$ is known, and the second is that undrained conditions exist in the field. Undrained behaviour of tailings in the field, however, cannot be taken for granted. It is a reasonable assumption for positive values of $\psi$ as considered above, but the assumption is likely to break down as soon as $\psi$ becomes close to zero or negative, i.e. if the material becomes dilative at any time during shearing. What happens is that shear localization can occur. More intense shearing on a shear band results in dilation in a thin zone, which is able to dilate as pore water is drawn from the larger adjacent volume into the shear band. This can happen relatively quickly as the flow volumes and path lengths are small. Constant volume conditions do not exist in the shear band. Somewhat more detail on this assumption is provided in Jefferies (1998), Jefferies and Been (2006) and Been and Ritchie (2008).

The resistance of sands and cohesionless tailings to cyclic loading is also primarily a function of the density or state parameter of the material, and other parameters such as the fabric and loading direction which are somewhat less important but not generally considered in simple analyses. Figure 5 illustrates how this has been done, starting from data such as that published for Canadian tailings sands by Garga and McKay (1984) which are shown in the inset on Figure 5. Laboratory testing for any particular material at a defined state can define what is termed a "cyclic resistance curve", by plotting the cyclic stress ratio in each test against the number of load cycles to liquefaction. When many materials are plotted on the same graph, the results are rather confusing (as for the Garga and McKay data) but it is found that each cyclic resistance curve is a similar shape. It is therefore possible to characterize each curve simply as the cyclic resistance ratio that corresponds to liquefaction failure at 15 cycles. There is no best number of cycles to consider - in this case 15 has been used since it corresponds approximately to the number of significant cycles in a magnitude 7.5 earthquake which is commonly used as a reference for liquefaction studies. Figure 5 therefore shows the cyclic resistance ratio for failure in 15 cycles $\left(\mathrm{CRR}_{15}\right)$ as a function of state parameter $\psi$ for cohesionless soils for which both cyclic strength and critical state line data are available. There is clearly some variation about the trend which is to be expected given that fabric and other parameters have not been included in the analysis. However, Figure 5 can be used as an initial estimate of cyclic strength prior to, or in the absence of, material specific cyclic test data.

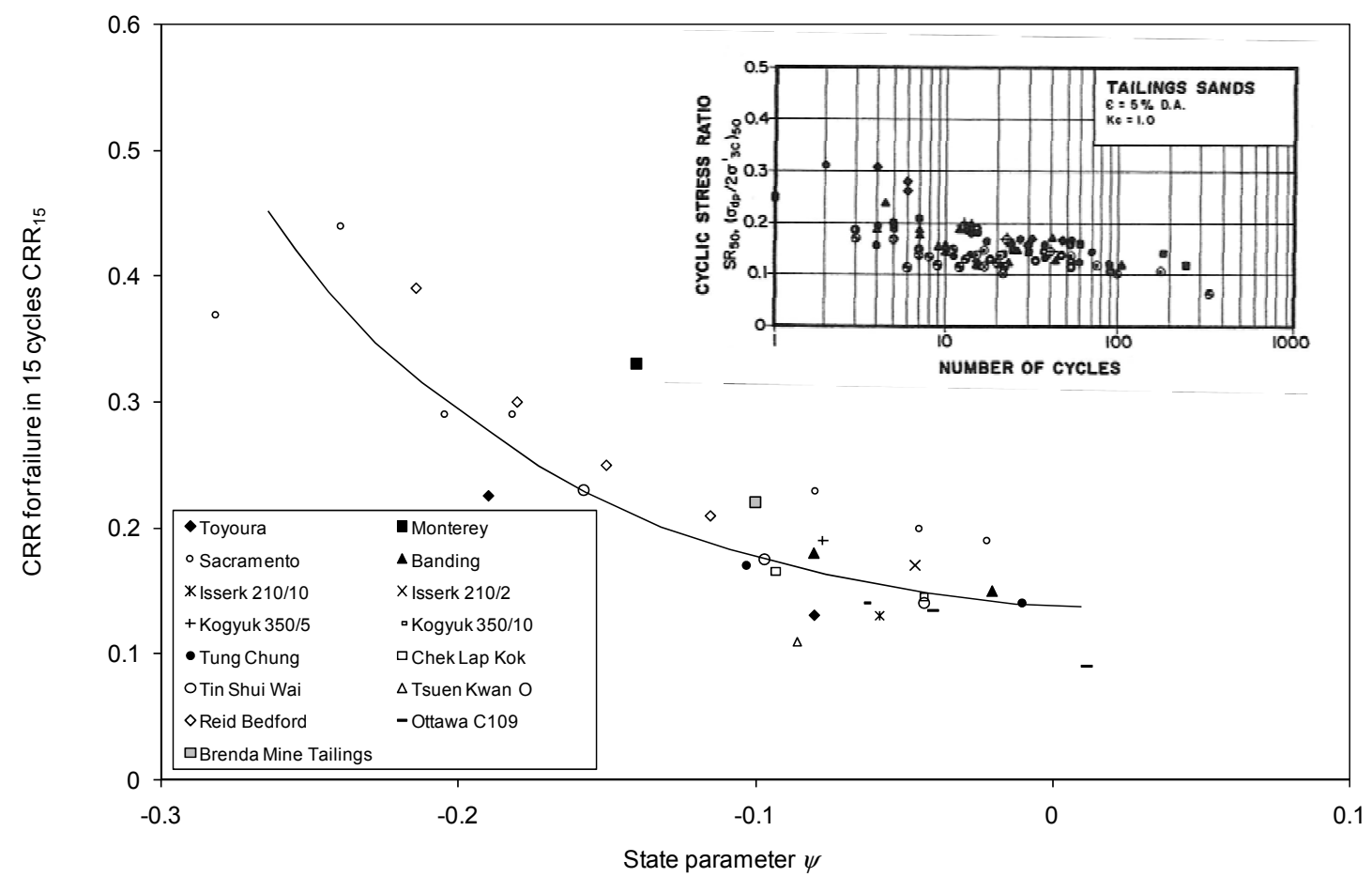

Figure 5 Cyclic strength of cohesionless materials as a function of state parameter. Inset shows cyclic strength curves for a number of tailings materials reported by Garga and McKay (1984) 


\section{Deposition and consolidation of paste tailings to in situ state}

Having shown how cyclic shear strength as well as static drained and undrained shear strength of tailings are determined by the state parameter, it remains to show how in situ state can be determined. In this regard, application of critical state theory to paste (or thickened) tailings is conceptually straightforward. Paste tailings are designed to be pumped and deposited with minimal water loss and particle segregation during deposition. Therefore, by the definition of the critical state as a state of shearing at constant stress and void ratio, paste tailings is at or slightly above its critical or steady state at the time of deposition. After deposition there might be some bleeding of excess water from the paste, desiccation by surface drying and loading by deposition of more material. The effect of these processes on the state of the deposited tailings is illustrated on Figure 6 which is a state diagram exactly like Figure 1.

After deposition in a layer of less than $1 \mathrm{~m}$ the material will be at a void ratio of about 1.2 (for this example) and a mean stress of 1 to $10 \mathrm{kPa}$, illustrated by the shaded oval on Figure 6. Bleeding of water may reduce the void ratio somewhat. However, the state will then change, illustrated by two paths on Figure 6 . One path shows desiccation where matric suctions give a relatively high mean effective stress and void ratios close to the shrinkage limit, followed by wetting as more material is deposited over the desiccated layers. Note that the actual stress path followed is most likely not the straight line shown - it is probably similar to the consolidation line until the shrinkage limit is reached. A second path is simple loading by additional deposition without desiccation. The final state of paste tailings in the stack is illustrated as being at a mean effective stress between 10 and $1000 \mathrm{kPa}$ (representing a depth from about 1 to $100 \mathrm{~m}$ ).

The stress paths described above can be modelled mathematically starting from knowledge of the state of the paste tailings on deposition and using self weight consolidation theory. A companion paper (Li et al., 2009) describes the process and time dependent stability of tailings stacks. A key requirement is that the state of the paste tailings immediately after deposition is known, however this is not generally the case. In practice, therefore, it is necessary to make some reasonable assumptions about the starting condition of the tailings based on past experience, and to check these design assumptions through field measurement of in situ state once the tailings facility is operational.

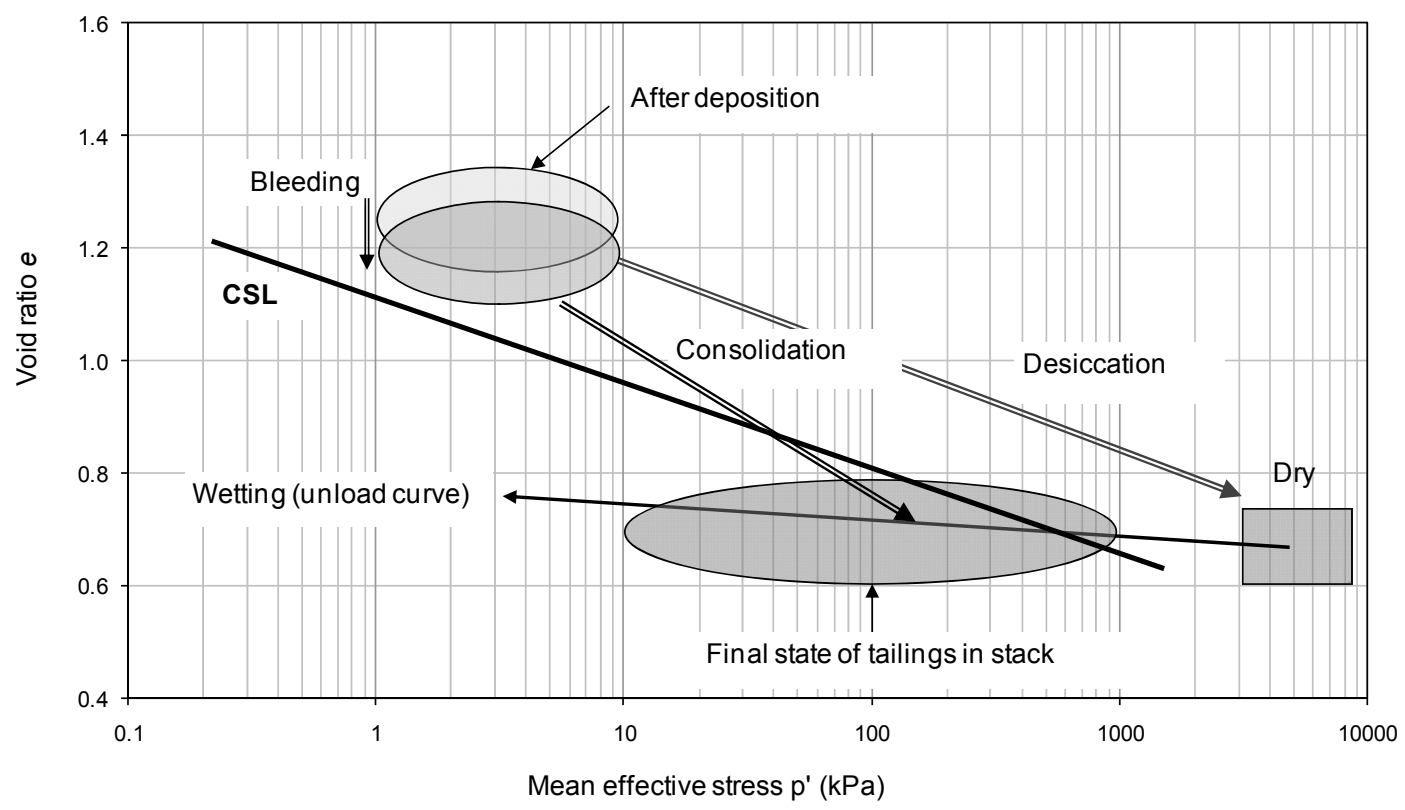

Figure 6 State changes in tailings after deposition at slightly looser than critical states at low mean stresses. Consolidation and desiccation lines are schematic, not actual, lines 
The current paper does not address the in situ measurement of state parameter, which is readily achieved through methods such as the cone penetration test (Been et al., 1986; Plewes et al., 1992; Jefferies and Been, 2006).

\section{Summary}

An understanding of liquefaction triggers and behaviour is important to the safe and economic design of paste and thickened tailings management facilities. Critical state soil mechanics provides such an understanding based on sound principles of plasticity theory and observations of real soil behaviour. Critical state soil mechanics also provides a mathematical model that can be implemented in engineering design. Essentially, engineering behaviour of tailings is described in terms of the state parameter which quantifies state in terms of density and stress level relative to conditions at the critical state. Equations, such as (3), define the residual or critical state strength when $\psi$ is positive, while a material specific version of Figure 3 can be generated to determine friction angle given negative values of $\psi$. The resistance to cyclic loads is captured in terms of a relationship between $\psi$ and the stress ratio causing liquefaction in 15 cycles of loading. A key challenge in design of a tailings facility is the ability to model the evolution and distribution of in situ state within a tailings deposit, which is shown schematically on Figure 6 . The above steps require some level of laboratory testing to determine consolidation properties, desiccation parameters for a dry environment, critical state line, static strength and cyclic stress ratio at a range of void ratios and stress levels. Finally, it is necessary to confirm the in situ state of any tailings deposit by direct measurement in the field. The cone penetration test is a reliable technique to estimate the state parameter through the tailings deposit.

\section{References}

Arulanandan, K. and Scott, R.F. (eds) (1993) Verification of numerical procedures for the analysis of soil liquefaction problems, Proceedings of the International Conference on the Verification of Numerical Procedures for the Analysis of Soil Liquefaction Problems, Vols. 1 and 2, A.A. Balkema, Rotterdam, the Netherlands.

Been, K. and Jefferies, M.G. (1985) A state parameter for sands, Géotechnique, 35, pp. 99-112.

Been, K., Crooks, J.H.A., Becker, D.E. and Jefferies, M.G. (1986) The cone penetration test in sands: part I, state parameter interpretation, Géotechnique, 36, pp. 239-249.

Been, K. and Ritchie, D. (2008) Designing mine tailings disposal for liquefaction, Proceedings 4th International Mining and Industrial Waste Management Conference, Rustenburg, South Africa, 11-13 March 2008, 11 p.

Bishop, A.W. (1973) The stability of tips and spoil heaps, Quarterly Journal of Engineering Geology, 6 (1973), pp. 335-376.

Casagrande, A. (1936) Characteristics of cohesionless soils affecting the stability of earth fills, Journal of Boston Society of Civil Engineers, 23, pp. 257-276.

Castro, G. (1969) Liquefaction of sands, PhD, Thesis, Harvard University, Cambridge, Mass, (Harvard Soil Mechanics Series 81).

Davies, M.P., Dawson, B.D. and Chin, B.G. (1998) Static liquefaction slump of mine tailings - a case history, Proceedings 51st Canadian Geotechnical Conference, Edmonton, Alberta, Canada October 4-8, Vol. 1, pp. 123-131.

De Alba, P.A., Seed, H.B., Retamal, E. and Seed, R.B. (1988) Analysis of dam failures in 1985 Chilean earthquake, Journal of Geotechnical Engineering, ASCE, 114, 12, pp. 1414-1434.

Fourie, A.B., Blight, G.E. and Papageorgiou, G. (2001) Soil liquefaction as a possible explanation for Merriespruit tailings dam failure. Canadian Geotechnical Journal, 38, 4, pp. 707-719.

Garga, V.K. and McKay, L.D. (1984) Cyclic triaxial strength of mine tailings, Journal of Geotechnical Engineering Division, ASCE, 110, GT8, pp. 1091-1105.

Ishihara, K., Yasuda, S. and Yoshida, Y. (1990) Liquefaction-induced flow failure of embankments and residual strength of silty sands, Soils and Foundations, 30, 3, pp. 69-80.

Jefferies, M.G. (1993) NorSand: a simple critical state model for sand, Géotechnique 43, pp. 91-103.

Jefferies, M.G. (1998) A critical state view of liquefaction. In Physics and Mechanics of Soil Liquefaction, P.V. Lade and J.A. Yamamuro (eds), Balkema, Rotterdam, pp. 221-235.

Jefferies, M.G. and Been, K. (2006) Soil liquefaction, a critical state approach. Taylor and Francis, London UK.

Lade, P.V. and Yamamuro, J.A. (eds) (1998) Proceedings International Conference on Physics and Mechanics of Soil Liquefaction, Johns Hopkins University, Baltimore, MD, September 10-11, 1998. 
Li, A.L., Been, K., Ritchie, D. and Welch, D. (2009) Stability of large thickened, non-segregated tailings slopes, Proceedings of the 12th International Seminar on Paste and Thickened Tailings, R.J. Jewell, A.B. Fourie, S. Barrera and J. Wiertz (eds), Australian Centre for Geomechanics, Perth, Australia, pp. 301-312.

Li, X.S. and Dafalias, Y.F. (2000) Dilatancy for cohesionless soils, Géotechnique, 50, pp. 449-460.

Manzari, M.T. and Dafalias, Y.F. (1997) A critical state two-surface plasticity model for sands, Géotechnique 47, pp. 255-272.

Mayne, P.W. (1980) Cam-clay predictions of undrained strength, Journal of the Geotechnical Engineering Division, ASCE, 106 (11), pp. 1219-1242.

Mittal, H.K. and Hardy, R.M. (1977) Geotechnical aspects of a tar sand tailings dyke, Proceedings of Conference on Geotechnical Practice for Disposal of Solid Waste Materials, Ann Arbor, Michigan, pp. 327-347.

Morgenstern, N. (2001). Geotechnics and mine waste management - update: Seminar on safe tailings dam construction, Gallivare, Swedish Mining Association, Natur Vards Verket, European Commission, pp. 54-67.

Newmark, N.M. (1965) Effects of earthquakes on dams and embankments, Géotechnique, 15, pp. 139-159.

Plewes, H.D., Davies, M.P. and Jefferies, M.G. (1992) CPT based screening procedure for evaluating liquefaction susceptibility, Proceedings 45th Canadian Geotechnical Conference, Toronto, Canada.

Schofield, A. and Wroth, C.P. (1968) Critical State Soil Mechanics, London, McGraw-Hill.

Seed, H.B., Seed, R.B., Harder, L.F. and Jong, H-L. (1988) Re-evaluation of the slide in the lower San Fernando dam in the earthquake of February 9, 1971, Report No UCB/EERC-88/04, Earthquake Engineering Research Centre, University of California at Berkeley. 